\title{
A carreira dos funcionários da educação A concepção de formação do Profuncionário
}

Dante Diniz Bessa*

\begin{abstract}
RESUMO: Ao registrar uma década do Profuncionário, apresento uma análise da concepção de formação do Programa que enfatiza a formação como chave da construção da identidade e da carreira profissional, considerando a dimensão formal, explicitada nos documentos político-normativos, que sintetizam, dialeticamente, o resultado da luta e a projeção de um novo momento da história dos funcionários da educação brasileira, que não pode prescindir da participação coletiva e pessoal de cada um.
\end{abstract}

Palavras-chave: Funcionários da educação. Identidade profissional. Carreira e formação.

\section{Introdução}

$\mathrm{U}$

ma carreira profissional, como a que os "funcionários da educação básica pública"1 lutam para consquistar, está condicionada por diversos aspectos, que vão das políticas de gestão democrática da educação às condições de trabalho na escola, passando pela regulamentação, pelo financiamento, pela avaliação, pelo plano de cargos e salários, pela oferta de formação.

Esses aspectos são ao mesmo tempo formais e situacionais, isto é, eles são definidos normativamente, porém, é bom lembrar, só se efetivam com o engajamento de cada funcionária e de cada funcionário, cuja atuação é situada. Ou seja, a carreira e sua construção envolvem uma dimensão formal, objetiva, normativa e uma dimensão situacional, pessoal, subjetiva, ativa.

Doutorando em Educação. Professor do Centro Universitário da Unidade Integrada Vale do Taquari de Ensino Superior (Univates) e da Universidade do Vale do Rio dos Sinos (Unisinos). São Leopoldo/RS Brasil. E-mail: <ddbessa@terra.com.br>. 
Enfatizo isso para deixar claro que a construção da carreira está diretamente vinculada com a identidade e com a formação profissional, conceitos que, neste texto, vão orientar a análise que proponho sobre a dimensão formal da formação concebida no Profuncionário, acompanhando o argumento apresentado no Parecer da Câmara de Educação Básica (CEB), do Conselho Federal de Educação (CNE) nº 9, de 2010, de que "a formação é a chave para a construção da identidade profissional e da carreira dos funcionários da Educação Básica Pública” (BRASIL, 2010a, p. 13).

Sendo assim, no texto apresentarei uma análise da concepção de formação do Programa Nacional de Formação Inicial em Serviço dos Profissionais da Educação Básica dos Sistemas de Ensino Público (Profuncionário), conforme define o Decreto Presidencial n⿳ำ 7.415, de 2010, frente às expectativas formalmente estabelecidas pela Política Nacional de Formação dos Profissionais da Educação Básica, sem levar em conta, nesse momento, o engajamento de funcionárias e funcionários nessa construção, o que deverá ser feito em outra oportunidade.

São três os motivos pelos quais coloco a concepção de formação do Profuncionário em análise, para pensar a construção da carreira profissional dos funcionários da educação: 1) o Profuncionário é o único programa de formação profissional, no Brasil, hoje, como política indutiva do Governo Federal, ofertado nacionalmente; 2) neste ano de 2016, o Profuncionário completa uma década de existência e, por isso, gostaria de prestar uma homenagem ao Programa; 3) o atual Plano Nacional de Educação tem como primeira estratégia da Meta 18 que, até junho de 2016, deveriam ter-se formados pelo menos 50\% dos funcionários da educação básica, porém, nos dez anos de Profuncionário, segundo estimativas do Ministério da Educação (MEC), apenas cerca de 130 mil funcionários foram matriculados em todo o Brasil, dos quais 90 mil concluíram a formação e 30 mil ainda estão em curso.

Se esses números não chegam a ser expressivos frente ao que se esperava há três anos, não podemos deixar de considerar que milhares de vidas já foram tocadas pela concepção de formação do Programa. Assim, eu diria que, aqui, o que está em pauta é a qualidade da concepção de formação e a necessidade do engajamento pessoal de funcionárias e funcionários, antes do que a quantidade de pessoas formadas, ainda que esse tema mereça atenção especial, por se tratar de uma política pública.

Nesse sentido, as questões que orientam a análise que proponho são as seguintes: a) o que faz da formação a chave da construção da identidade e da carreira profissional?; b) como a concepção de formação do Profuncionário se situa e contribui para que os funcionários se situem frente à projeção político-normativa da identidade e da carreira profissional?

A análise seguirá três passos. No primeiro, procuro estabelecer uma base conceitual a partir da qual é possível entender a formação como chave na construção da carreira. Essa base será tomada à teoria segundo a qual a identidade profissional e a carreira são 
construídas no entrelaçamento entre as definições socialmente estabelecidas (aqui as definições político-normativas nacionais) e as biografias individuais (engajamento pessoal no projeto social que contempla um projeto de vida). No próximo passo, examino os documentos político-normativos que definem os princípios e objetivos da formação e os preceitos e diretrizes para elaboração de planos de carreira, para identificar a projeção que fazem. No terceiro passo, apresento os pressupostos da concepção de formação do Profuncionário, especialmente aqueles pertinentes à identidade profissional e à carreira, com vistas a explicitar como o Programa responde à projeção político-normativa e que projeção faz a própria concepção sobre a identidade e a carreira profissional dos funcionários.

\section{Formação: chave para a construção da identidade e da carreira profissional}

Para pensarmos o que faz da formação a chave da construção da identidade e da carreira profissional é interessante partir de um conceito de profissão.

Antes de apresentar esse conceito, contudo, é bom lembrar que a profissionalização do trabalho faz parte dos processos de transformações socioeconômicas da modernidade.

Do ponto de vista histórico, então, a origem das profissões remonta às corporações de ofício, cujo auge foi atingido no século XV europeu.

Simplificadamente, podemos dizer que as corporações de ofício eram comunidades de trabalho especializado, comandadas por oficiais que, além do direito de realizar, detinham conhecimentos "secretos" sobre esse trabalho, nos quais os aprendizes eram iniciados, em muitos casos, por milhares de horas práticas. Nesses milhares de horas práticas os aprendizes se aperfeiçoavam nas técnicas e habilidades e eram educados nos valores e no modo de agir do ofício, isto é, nas corporações eles eram formados técnica e moralmente pela comunidade.

Já aí podemos ver os primórdios da divisão técnica e social do trabalho, bem como a relevância da formação para ser aceito no corpo de um ofício.

Como transformação moderna das corporações de ofício, as profissões diferem daquelas por três motivos: 1) pela intensificação da divisão técnica e social do trabalho, que distanciou a concepção da execução e levou à 2) separação espaço-temporal entre trabalho e formação, de modo a que esta antecede e antecipa aquele, e 3) o trabalho profissional se torna um bem social, acessível a qualquer um que reúna condições socioculturais e econômicas para passar por um processo formativo.

Conceber o trabalho passa a ser específico de profissionais com formação especializada para isso, enquanto executar o trabalho se torna atividade de técnicos com formação média e, na maior parte dos casos, atividades puramente manuais, para as quais não é exigida nenhuma formação específica, senão treinamentos. 
Da perspectiva conceitual, a partir de pesquisadores como Eliot Freidson², Naira Franzoi $^{3}$ e Claude Dubar ${ }^{4}$, podemos pensar uma profissão como um tipo de trabalho especializado, oficial e socialmente reconhecido e que requer conhecimentos específicos a serem adquiridos no campo da formação. Trabalho pelo qual os profissionais são remunerados.

Para que um indivíduo tenha o direito de exercer uma profissão, portanto, precisa estar apto e autorizado, isto é, precisa ser formado para tanto, segundo diretrizes oficial e socialmente reconhecidas.

Chama nossa atenção Naira Franzoi (2006) de que se não houver o efetivo exercício pelos profissionais não há profissão, uma vez que esta não pode existir plenamente se não houver profissionais concretizando-a no trabalho.

Nesse sentido, os profissionais precisam reconhecer-se a si mesmos e serem reconhecidos pelo outro (instituições e coletividade do trabalho) como aptos para agir profissionalmente, porque se apropriaram dos conhecimentos da profissão para responder a expectativas sociais em relação ela, definida normativamente pelo direito e planejada pela carreira e na formação.

Esse reconhecimento de si implica a assunção, por parte dos profissionais, do compromisso social da profissão e da autonomia pessoal para exercê-la, o que caracteriza uma dimensão ética da formação, para além dos conhecimentos específicos.

Podemos dizer, enfim, que o reconhecimento de si constitui a identidade dos profissionais, pois define, para eles, individualmente, o pertencimento a uma profissão, a qual ajudam a construir nas atividades diárias de trabalho.

O direito à formação profissional significa, assim, uma "autorização" social aos indivíduos para exercer uma profissão. Autorização que os coloca no compromisso de contribuir com a realização de um projeto social no qual se engajam e no compromisso com o desenvolvimento da própria profissão, de maneira que nesse engajamento possam realizar o seu projeto de vida pessoal.

O entrelaçamento entre projeto social e projeto de vida pessoal remete à tese de Dubar (2005) segundo a qual a formação profissional é um processo de socialização com o qual identidades são construídas.

E vale acrescentar, nesse entrelaçamento também são construídas a(s) carreira(s) profissional(is), se entendermos carreira como o processo de definição da natureza do trabalho específico da profissão; dos objetivos e compromissos sociais da profissão; de quem pode exercer a profissão; do nível e do tipo de formação que a profissão requer; das funções e atividades próprias da profissão; dos valores morais e princípios éticos que devem orientar a conduta dos profissionais; dos critérios de progressão dos profissionais no emprego; da remuneração justa a cada avanço na progressão.

Enfim, a carreira expressa uma visão de mundo da profissão, construída pelos profissionais no seu exercício e na luta social, formalizada normativamente pelo direito. 
Segundo Dubar, a construção da identidade (e da carreira, para mim) é um processo em que se articulam duas transações interdependentes: uma ocorre no indivíduo em si, é subjetiva e concerne a uma trajetória biográfica; a outra ocorre na relação do indivíduo com as instituições, é objetiva e concerne a um movimento relacional entre o biográfico e o institucional. Daquele processo resultam uma "identidade para si" dos indivíduos (correlata ao reconhecimento de si) e uma "identidade para o outro" (correlata ao reconhecimento de si pelo outro, intersubjetivamente, ao reconhecimento social nas instituições e ao reconhecimento legal pelo direito).

Considerando, então, que identidade e carreira profissional são processuais, são construídas e reconstruídas pela representação subjetiva do reconhecimento do outro em dinâmicas práticas da história da profissão e da vida dos profissionais, é importante compreender uma diferenciação que Dubar (2009) propõe para pensar essa processualidade.

O autor pensa a construção e reconstrução de identidade a partir de "processos históricos ao mesmo tempo coletivos e individuais, que modificam a configuração das formas identitárias definidas como modalidades de identificação" (DUBAR, 2009. p. 14).

Segundo Dubar, podemos classificar as "formas identitárias" em dois tipos, que se relacionam entre si: "forma comunitária" e "forma societária".

As formas comunitárias pressupõem uma comunidade organizada na qual já estão pré-atribuídos lugares e nomes aos indivíduos, passados de geração para geração. Aqui é a primazia das identificações para o outro. Identidade como pertencimento.

Já as formas societárias de construção da identidade pressupõem "a existência de coletivos múltiplos, variáveis, efêmeros, aos quais os indivíduos aderem" (Dubar, 2009, p. 15). Aqui é a primazia da identidade para si. Identidade como escolha pessoal.

A identidade profissional, pensada por essa perspectiva da participação do indivíduo na vida social como alguém capaz de exercer uma profissão, é resultante de diferentes processos de socialização.

Enquanto isso, a formação profissional deve ser pensada como um desses processos de socialização pelo qual um indivíduo, ao escolher uma profissão, é colocado na relação com o acúmulo histórico de conhecimentos e valores, com outros profissionais da mesma profissão e de outras profissões próximas, além de colocá-lo em relação com as normas, objetivos e funções oficial e socialmente reconhecidos para a profissão que escolheu.

Resumindo: a formação é chave para a construção da identidade e da carreira profissional na medida em que é a principal fonte de conhecimentos e valores necessários para que alguém possa estar apto e autorizado a exercer uma profissão, sentir-se pertencendo a ela e desafiado a participar de sua construção a partir do trabalho cotidiano e das relações com o(s) coletivo(s) profissional(is), seja no local de trabalho seja nos sindicatos ou associações seja na interlocução, de igual para igual, com os profissionais especializados na produção dos conhecimentos da profissão. 


\section{Reconhecimento e expectativas político-normativas}

Nunca é demais lembrar que a valorização profissional dos funcionários da educação é um direito que se situa historicamente em um processo de luta, uma vez que, do ponto de vista histórico, a categoria, como sugere João Monlevade (2014), foi levada à invisibilidade social, à subalternidade política, à marginalização pedagógica, à sub-valorização profissional e à indefinição funcional.

Essa situação que os funcionários lutam para transformar está relacionada com uma identidade historicamente construída, em que nem os outros nem os próprios funcionários se reconhecem como participantes do processo educativo escolar, porque seu trabalho sempre foi tratado como serviço auxiliar, de apoio ao ensino. Enfim, o trabalho que garante as condições materiais da educação escolar nunca foi considerado educativo.

Nesse contexto, os funcionários tiveram dificultadas as condições para construir uma identidade afirmativa como profissionais da educação, de modo a se engajarem num projeto social que contribuísse com seus projetos de vida pessoal.

Partindo desse pressuposto histórico, a luta por valorização e reconhecimento profissional dos funcionários, que se traduz em incessante trabalho de conquista, garantia e ampliação de direitos, deve contar com o engajamento intenso de cada funcionária e de cada funcionário e deve envolver a todos os profissionais da educação, a comunidade escolar e a cidadania em geral, já que sua finalidade é a transformação na qualidade da educação pública, como deixa claro o Decreto Presidencial nº 7.415, de 2010, ao definir os princípios e objetivos da Política de Formação.

A Política de Formação, dialeticamente, responde à luta histórica dos funcionários reconhecendo-os como profissionais da educação e instituindo o direito à formação profissional como necessária à valorização, ao mesmo tempo em que projeta a identidade e a carreira a partir da formação, que deve articular teoria e prática e ter conhecimentos científicos e específicos da natureza da função como fundamentos.

Mas, que projeção sobre a identidade e a carreira pode ser encontrada na Política de Formação? Quanto a isso, destaco o seguinte:

» A formação profissional dos funcionários é afirmação do compromisso do governo federal "com projeto social, político e ético que contribua para a consolidação de uma nação soberana, democrática, justa, inclusiva e que promova a emancipação dos indivíduos e grupos sociais" (BRASIL, 2010, p. 1), de onde se pode deduzir a expectativa que os funcionários da educação possam se engajar nesse projeto como coconstrutores e não apenas como beneficiários.

» A valorização profissional pela formação há que ser acompanhada de melhorias nas condições de trabalho com a definição de planos de carreira, de jornada e de 
remuneração de modo que os funcionários e outros trabalhadores possam escolher se identificar e permanecer na profissão.

» Os funcionários profissionalizados devem melhorar o "ambiente escolar" e contribuir, assim, na transformação da qualidade da educação.

O Decreto é posterior à fixação das Diretrizes Nacionais para os Planos de Carreira e Remuneração dos Funcionários da Educação Básica Pública, por meio da Resolução CNE/CEB nํ5, de 2010, orientada pelo Parecer CNE/CEB nํ 9, de 2010.

Do Parecer destaco a referência que faz ao processo coletivo e à interação das diversas atividades na escola, quando se pensa em educação para a formação de cidadãs e cidadãos. Ou seja, todas as atividades escolares são reconhecidas como relevantes para o processo educativo da cidadania que pode vir a se engajar naquele projeto social indicado na Política de Formação.

O Parecer pressupõe que a formação profissional possa prover os funcionários das condições para que ajam intencionalmente nas atividades de trabalho, como educadores profissionais integrantes do movimento coletivo que é o processo educativo, tal como já estava declarado no documento intitulado Por uma política de valorização dos trabalhadores em educação: em cena, os funcionários de escola, documento que antecipa e orienta o governo federal na implantação da Política de Valorização dos funcionários:

Nesse cenário, merendeiras precisam, também, cuidar da educação alimentar, bibliotecários, ajudar na construção do hábito da leitura e da educação literária, secretários devem colaborar com o processo avaliativo do ensino e da aprendizagem, configurando-se a instituição de novas identidades funcionais (BRASIL, 2004, p. 16).

Na Resolução encontramos, nos preceitos e diretrizes para a elaboração de planos de carreira, a centralidade da formação: tanto o acesso por concurso público, como a progressão salarial, a jornada parcialmente dedicada a tarefas de gestão e formação, consoante o projeto político-pedagógico da escola e participação na elaboração e no planejamento, na execução e na avalição do projeto político-pedagógico da escola e da rede de ensino têm como critério a formação inicial e continuada.

Assim, a necessidade de (re)construir a identidade e definir a carreira a partir da formação, colocada pela Política de Formação como condição para a valorização e para o reconhecimento, sugere que os funcionários só serão reconhecidos e valorizados se puderem se transformar em outros, ou seja, se souberem e puderem, a partir da formação, atender as expectativas oficiais e socialmente projetadas que, hoje, não poderiam atender, segundo a atual identidade "para si" e "para os outros", resultante do movimento histórico. 


\section{A concepção de formação do Profuncionário}

As informações históricas, conceituais e político-normativas apresentadas anteriormente deixaram claro: 1) que a formação é central para a construção da identidade e da carreira bem como para o reconhecimento e valorização profissional dos funcionários da educação e 2) que o núcleo da formação são os conhecimentos específicos sem os quais os profissionais não são reconhecidos como aptos para exercer a profissão.

Frente a isso, devemos, agora, pensar a maneira como a formação em curso no Brasil, ofertada pelo Profuncionário, é concebida e como contribui para que os funcionários possam se posicionar frente às projeções sobre sua identidade e carreira profissional.

Pois bem, o ponto de partida da concepção de formação do Profuncionário é os sujeitos da/em formação: funcionários da educação em efetivo exercício de suas funções.

São pessoas que sabem um saber construído na vivência cotidiana de seu fazer. Sabem um saber fazer que exprime competências adquiridas e construídas no próprio fazer.

Esses aspectos da vivência e do saber fazer dos estudantes, que lhes dão uma identidade atual, precisam ser desconstruídos e reconstruídos para que uma nova identidade profissional possa ser criada, se for o caso (BRASIL, 2014b, p. 53).

A condição desses sujeitos exige que a formação seja pensada como "formação em serviço" e, por isso, o Profuncionário reconhece os conhecimentos construídos na experiência de trabalho como relativos a uma identificação já existente que não pode ser ignorada pela formação profissional.

Ao contrário, a formação concebida pelo Profuncionário coloca em relação conhecimentos e valores da experiência e conhecimentos técnico-científicos específicos, que constituem, parcialmente, a identidade herdada da história e da vida e a identidade projetada.

Essa relação, que os próprios funcionários precisam estabelecer, é provocada por meio de atividades nas quais novos conhecimentos poderão ser construídos, desde que os funcionários possam assumir uma postura crítica frente à realidade de seu trabalho na escola e (trans)formar a si mesmos e ao ambiente escolar. Com isso, os funcionários poderão afirmar seu pertencimento à categoria de "profissionais da educação", ao se investir na produção dos conhecimentos que lhes possibilitarão planejar e atuar como educadores em espaços escolares específicos.

O que isso significa em termos de concepção de formação?

Tendo em conta o trabalho como princípio educativo, isso significa que a experiência dos funcionários no trabalho não pode ser desconsiderada como elemento de formação e, por isso, no Profuncionário, a formação é concebida como encontro e confronto intelectual, entre conhecimentos técnico-científicos e saberes produzidos nas situações de trabalho. Uma formação, portanto, que não antecede ao trabalho e propõe que os funcionários sejam protagonistas do seu aprendizado e da construção da identidade e da carreira profissional. 
...o Profuncionário pretende criar condições para que o estudante, funcionário da educação, desconstrua sua identidade profissional "tradicional" (porteiro, zelador, merendeira, auxiliar, servente) e a reconstrua como técnico em educação, cuja especificidade abrange competências e conhecimentos de educador, de gestor de espaços escolares e da própria escola e de cidadão, sem se descuidar da humanização que ela pode promover (BRASIL, 2014b, p. 86-7).

A proposta de formação do Profuncionário, do ponto de vista pedagógico, sugere que a transformação da identidade profissional é um processo que passa pela problematização do que os funcionários fazem na escola, desde a experiência do trabalho.

É problematizando sua vivência e as práticas escolares que o estudante poderá sentir e perceber os conhecimentos de que precisa para compreender e fazer de outro jeito (e, talvez, com outras novas intenções) o que faz todos os dias, ou partir para ações novas, criativas, que revelem sua compreensão científica e pedagógica dos problemas e dos meios para superá-los. Problematizar significa confrontar conhecimentos, valores e habilidades já presentes no fazer cotidiano com outras concepções, visões, teorias, propostas e paradigmas (BRASIL, 2014b, p. 73-4).

Do ponto de vista do currículo, assim como a experiência inaugural do Projeto Arara Azul, no Mato Grosso, quanto à formação profissional dos funcionários, os cursos do Profuncionário se estruturam em três núcleos:

» O Núcleo da Formação Pedagógica, integrado por conhecimentos das ciências e da filosofia da educação, com vistas à construção da identidade de educador, gestor da educação, isto é, "como profissional da educação".

» O Núcleo da Formação Específica, integrado por conhecimentos técnico-científicos relativos à natureza das funções específicas de cada habilitação, com vistas à construção das identidades específicas que diferenciam os funcionários entre si e em relação aos professores e pedagogos.

» O Núcleo da Prática Profissional Supervisionada, integrada por um conjunto de atividades de pesquisa, reflexão e exercícios técnicos que possibilita aos funcionários planejar ações nas quais possam problematizar a realidade do trabalho, ao confrontar os conhecimentos técnico-científicos introduzidos pelos cadernos de conteúdos com os conhecimentos da experiência no trabalho.

Esses três núcleos são articulados transversalmente entre si e em torno do tema "escola", lugar de atuação profissional dos funcionários e, portanto, eixo central da formação. O tema escola atravessa e é atravessado por todas as disciplinas dos cursos, sendo problematizado a partir de outros temas relevantes para a formação do educador que atua em espaços educacionais específicos, como se pode ver no quadro a seguir: 


\begin{tabular}{l|l}
\hline Habilitação & Temas transversais \\
\hline $\begin{array}{l}\text { Formação Pedagógica (comum a todas as } \\
\text { habilitações) }\end{array}$ & $\begin{array}{l}\text { Educação, Trabalho, Identidade, Cidadania } \\
\text { e Gestão Democrática }\end{array}$ \\
\hline Secretaria escolar & Gestão democrática e participativa \\
\hline Multimeios didáticos & $\begin{array}{l}\text { Linguagem, Arte, Tecnologias da } \\
\text { Informação e da Comunicação (TIC) }\end{array}$ \\
\hline Alimentação escolar & $\begin{array}{l}\text { Alimentação saudável e nutritiva, Política } \\
\text { Alimentar, Produção de alimentos, Higiene }\end{array}$ \\
\hline Infraestrutura escolar & $\begin{array}{l}\text { Meio ambiente, Espaço escolar, Higiene e } \\
\text { Segurança }\end{array}$ \\
\hline
\end{tabular}

Com essa estrutura curricular o Profuncionário prioriza uma formação transversal antes do que uma formação disciplinar e vertical em relação à experiência dos funcionários na escola, de modo a que eles se sintam e se identifiquem, em suas atividades, como profissionais e gestores da educação.

Assim, no núcleo da Prática Profissional Supervisionada (PPS) não se vai somente aplicar ou usar conhecimentos adquiridos nos núcleos da Formação Pedagógica e da Formação Específica. Ao contrário, a PPS é um lugar e um momento em que o aplicar e usar conhecimentos se tornam problemáticos, críticos, exigindo compreensão, explicação, construção e reconstrução do saber e do saber fazer (BRASIL, 2014b, p 80).

Na formação concebida pelo Profuncionário, portanto, os conhecimentos da experiência são valorizados como fundamentais para a reconstrução da identidade profissional e da carreira.

Mas, como essa reconstrução da identidade pela formação pode ser diagnosticada?

Pode ser diagnosticada por um processo de avaliação formativa processual e dialógica no seu acontecer, diagnóstica e participativa quanto ao método e emancipatória em seu objetivo. Como processo dialógico e participativo, notamos que a avaliação pressupõe autoavaliação mediada.

Essa autoavaliação mediada é feita por meio de dois instrumentos: um memorial reflexivo e um relatório analítico-descritivo das atividades de PPS.

O memorial possibilita que os funcionários, por meio da produção escrita, sejam ativos intelectualmente, ao refletir sobre suas atividades no trabalho, na medida em que registram, narrativamente, a sua trajetória de vida e de trabalho, senão, pelo menos, a sua trajetória num dos cursos do Programa, de modo a poder perceber e planejar mudanças nas atividades e mudanças na própria escola, ao confrontar, pela escrita, o modo como executavam suas funções com o modo como passaram a executá-las, com a introdução de conhecimentos técnico-científicos na experiência de trabalho. 
Já o relatório das atividades de PPS é um documento no qual os funcionários registram, para a história da profissão, a memória das transformações da profissão e disponibilizam, para a categoria e para as próximas gerações, a experiência histórica da produção de conhecimentos específicos, da qual são protagonistas.

Nesse sentido, os instrumentos de avaliação do Profuncionário são instrumentos de autoavaliação que fazem a mediação da produção de si dos funcionários pela escrita e pelo diálogo com quem os acompanha nas atividades formativas: tutores, professores e, sobretudo, os coletivos da profissão e do trabalho na escola.

\section{Enfim...}

A análise da concepção de formação do Profuncionário a partir do referencial conceitual escolhido possibilitou compreender que os documentos político-normativos, dialeticamente, expressam conquistas dos funcionários da educação e projetam uma nova identidade profissional, que passa pela construção da carreira, cuja chave é a formação.

Essa nova identidade introduz os funcionários na categoria de "profissionais da educação", corresponsáveis pela qualidade da educação básica pública brasileira, junto com professores, pedagogos, comunidade escolar e gestores, corresponsáveis por uma educação ligada a um projeto social no qual podem se engajar a partir de seus projetos pessoais de vida.

A parte da responsabilidade que cabe aos funcionários circunscreve-se às especificidades de suas funções, de modo que a nova identidade profissional, por um lado, deve uni-los aos professores e pedagogos, porque com eles há algo em comum: os conhecimentos pedagógicos que os habilitam a participar nos processos escolares como educadores, em espaços específicos e como gestores da educação, e, assim, terem uma mesma representação sindical.

Por outro lado, essa identidade os diferencia de professores e pedagogos na medida em que são responsáveis pela qualidade do ambiente escolar, de modo geral, e os diferencia entre si, na medida em que o ambiente escolar é múltiplo e cada espaço exige conhecimentos específicos para ser gerido com finalidade educativa.

Ao considerarmos que a identidade atual dos funcionários, construída historicamente em relações sociais que não reconheceram nem valorizaram suas funções, ditas auxiliares, de apoio ao ensino, nem tampouco os trabalhadores ocupados com essas funções como relevantes para a educação escolar, podemos dizer que a projeção de uma nova identidade pela qual o trabalho e os trabalhadores sejam valorizados implica em um processo de desconstrução e reconstrução da identidade. 
Um processo cujas condições objetivas, estabelecidas normativamente, são necessárias, mas não são suficientes, já que exigem o engajamento, a participação coletiva e pessoal das funcionárias e dos funcionários na formação que os torna aptos e os autoriza a exercer a profissão e a construir a carreira e a identidade profissional.

Recebido em março de 2016 e aprovado em junho de 2016

\section{Notas}

1 No Parecer CNE/CEB № 9, de 2010, por sugestão de profissionais da educação básica presentes na audiência pública realizada em Recife-PE, com vistas à elaboração do próprio documento, a relatora adota a nomenclatura de "funcionários da educação básica pública" para os profissionais da educação identificados, na categoria III do Art. 61 da Lei 9.394, de 1996, cuja redação foi alterada por meio da Lei nº 12.014, de 2009, como "trabalhadores em educação, portadores de diploma de curso técnico ou superior em área pedagógica ou afim". Da minha parte, vou seguir essa nomenclatura, abreviando-a ora para "funcionários da educação" ora para, simplesmente, "funcionários".

2 Eliot Lazarus Freidson (1923-2005), sociólogo norte americano, professor na Universidade de Nova York, considerado um dos fundadores da sociologia das profissões.

3 Naira Lisboa Franzoi , doutora em educação, professora do PPGEDU/UFRGS.

4 Claude Dubar (1945-2015), sociólogo francês que teve entre seus principais temas de pesquisa as identidades profissionais.

\section{Referências}

BRASIL. Por uma política de formação dos trabalhadores em educação: em cena os funcionários de escola. Brasília: MEC, SEB, 2004.

. Parecer CNE/CEB no 9, de 05 de maio de 2010.

Resolução CNE/CEB n⿳0 5, de 03 de agosto de 2010.

Decreto Presidencial n⿳⺈ 7.415, de 30 de dezembro de 2010.

Lei n⿳0 13.005, de 25 de junho de 2014a.

. Ministério da Educação. Secretaria de Educação Profissional e Tecnológica. Orientações Gerais. Cuiabá: Universidade Federal de Mato Grosso / Rede e-Tec. 4. ed. atualizada e revisada. Brasil, $2014 b$.

DUBAR, Claude. A socialização: construção das identidades sociais e profissionais. Tradução de Andréa Stahel M. da Silva. São Paulo: Martins Fontes, 2005.

A crise das Identidades: A Interpretação de uma Mutação. Tradução de Mary Amazonas Leite de Barros. São Paulo: EDUSP, 2009. 
FRANZOI, Naira Lisboa. Entre a formação e o trabalho: trajetórias e identidades profissionais. Porto Alegre: Ed. UFRGS, 2006.

FREIDSON, Eliot Lazarus. Para uma análise comparada das profissões: a institucionalização do discurso e do conhecimento formais. Tradução de João Roberto Martins Filho. Revista Brasileira de Ciências Sociais. São Paulo, v. 11, n. 31, p. 141-154, 1996.

MONLEVADE, João Antônio Cabral de. História e construção da identidade: compromissos e expectativas. Retratos da Escola. v.3, n. 5, Brasília: CNTE jul/dez 2009.

Profissionalização ou terceirização? O futuro dos funcionários de educação à luz das conquistas e desafios do presente. Brasília: Edição do autor, 2014. 


\section{The career of education workers The concept of positive worker training}

ABSTRACT: By registering a decade of Positive employee training, I present an analysis of the formation program design that emphasizes training as key to constructing a professional career identity. It considers the formal dimension, explicit in the political and normative documents, which synthesize dialectically the result of the struggle and the projection of a new moment in the history of Brazilian education workers and which cannot do without the collective and personal participation of each.

Keywords: Education workers. Professional identity. Career and training.

\section{La carrière des fonctionnaires de l'éducation La conception de la formation selon le Profuncionário*}

RÉSUMÉ: Alors que le Profuncionário atteint ses dix ,je presente ici une analyse de la conception de la formation du Programme qui met en avant la formation comme la clé de la construction de l'identité et de la carrière professionnelle, en considérant la dimension formelle, explicitée par les documents politico-normatifs qui synthétisent, dialectiquement, le résultat de la lutte et la projection d'un nouveau moment de l'histoire des fonctionnaires de l'éducation brésilienne, qui ne peut se faire sans la participation collective et personnelle de chacun.

Mots-clés: Fonctionnaires de l'éducation. Identité professionnelle. Carrière et formation.

* Nom du programme donné à la formation des fonctionnaires de l'éducation.

\section{La carrera de los empleados de la educación La concepción de formación del programa Profuncionario}

RESUMEN: Cumplida una década del Profuncionario, presento un análisis de la concepción de formación de este programa que enfatiza la formación como clave para la construcción de la identidad y de la carrera profesional, teniendo en cuenta la dimensión formal expresada en los documentos políticos normativos que sintetiza, de forma dialéctica, el resultado de la lucha y la proyección de un nuevo momento de la historia de los empleados de la educación brasileña, que no puede prescindir de la participación colectiva y personal de cada uno.

Palabras clave: Empleados de la educación. Identidad profesional. Carrera y formación. 